\title{
Evaluation of the effect of selective serotonin reuptake inhibitors on bone mineral density: an observational cross-sectional study
}

\author{
E. Ak • S. D. Bulut • S. Bulut • H. A. Akdağ • G. B. Öter • \\ H. Kaya • O. B. Kaya • C. B. Șengül • C. Kısa
}

Received: 23 May 2014 / Accepted: 13 August 2014 / Published online: 4 September 2014

(C) The Author(s) 2014. This article is published with open access at Springerlink.com

\begin{abstract}
Summary Sixty patients diagnosed with generalized anxiety disorder and treated with either paroxetine, sertraline, or citalopram for at least 12 months were enrolled in this study, and the bone mineral density (BMD) of the patients was compared with that of 40 healthy volunteers. Selective serotonin reuptake inhibitor (SSRI) therapy in generalized anxiety disorder was found to be related with decreased BMD values. Introduction The objectives of this study were to evaluate the effect of SSRI therapy on BMD in postmenopausal women diagnosed with generalized anxiety disorder (GAD) and to identify the effects of the duration of disease and treatment on risk factors for osteoporosis.

Methods Sixty patients diagnosed with GAD and treated with paroxetine, sertraline, or citalopram from the SSRI group for at least 12 months were enrolled. Social demographic features, the Hamilton Anxiety Scale (HAS) results, and the Hamilton Depression Scale (HDS) scores of all the patients were assessed. The BMD of the patients was measured by dual-
\end{abstract}

\author{
E. Ak \\ Psychiatry Department, Medical Park Gaziantep Hospital, \\ Gaziantep, Turkey \\ e-mail: emine.ak@hotmail.com \\ S. D. Bulut $(\bowtie) \cdot$ C. Kisa \\ Psychiatry Department, Dışkapı Yıldırım Beyazıt Educational and \\ Traditional Hospital, Ankara, Turkey \\ e-mail: dr_sdbulut@yahoo.com \\ C. Kisa \\ e-mail: cebrailkisa@hotmail.com \\ S. Bulut \\ Psychiatry Department, Gülhane Military Medical Academy, \\ Ankara, Turkey \\ H. A. Akdă \\ Psychiatry Department, Bursa State Hospital, Bursa, Turkey \\ e-mail: htcalkan@yahoo.com
}

energy X-ray absorptiometry (DXA) at the femoral and lumbar regions. The patients were divided into three groups which are the paroxetine, sertraline, and citalopram groups. The BMD of the patients was compared with that of 40 healthy volunteers.

Results The L2-L4, total lumbar vertebrae, femoral intertrochanteric, total femoral Z-scores, and femoral Ward's region $\mathrm{T}$-scores of the treatment group were lower than the median T- and Z-scores of the control group $(p<0.05)$. Of the treatment groups, the femoral neck, trochanteric and intertrochanteric T- and Z-scores, total femoral T- and Zscores, and femoral Ward's T- and Z-scores of the sertraline group were significantly lower than the BMD values measured at the identical regions in the paroxetine and citalopram groups $(p<0.05)$.There was a significant negative correlation between the duration of treatment and the BMD values.

Conclusion SSRI therapy in GAD was found to be related with decreased BMD values. Further randomized controlled studies are warranted to determine whether SSRI use is a risk

G. B. Öter

Psychiatry Department, Ankara Numune Educational and Traditional Hospital, Ankara, Turkey

e-mail: gzdbsftr4@hotmail.com

H. Kaya

Psychiatry Department, 25 Aralık State Hospital, Gaziantep, Turkey e-mail: dr.kaya.hasan@gmail.com

O. B. Kaya

Psychiatry Department, Dr. Ersin Arslan State Hospital, Gaziantep, Turkey

e-mail: ozlembolat@gmail.com

\section{B. Șengül}

Faculty of Medicine, Psychiatry Department, Pamukkale University,

Denizli, Turkey

e-mail: melikeceyhan@gmail.com 
factor for osteoporosis; such studies should investigate these factors by performing BMD assessments before treatment.

Keywords BMD $\cdot$ GAD $\cdot$ Osteoporosis $\cdot$ SSRI

\section{Introduction}

Generalized anxiety disorder (GAD) is a chronic anxiety disorder with a lifetime incidence rate of 4-6\% that could be accompanied by other physical diseases. Selective serotonin reuptake inhibitors are the most commonly prescribed antidepressants for GAD. Generalized anxiety disorder and selective serotonin reuptake inhibitor therapy could be accompanied by various biological alterations throughout the systems of the body. In recent years, one of the most investigated biological alterations is osteoporosis. According to the World Health Organization (WHO), osteoporosis (OP) is a silent epidemic characterized by a predisposition to enhanced bone fragility and an increased risk of fracture [1]. PattersonBuckendahl et al. showed that anxiety disorders influence bone metabolism by demonstrating that psychological stress causes a decrease in osteocalcin levels which increase during the construction of bone and concluded that chronic stress has a negative influence on growth [2]. In another study, concerning bone mineral density and anxiety-depression symptoms, it was shown that increased anxiety levels are correlated with decreased bone mineral density [3].

Although the studies investigating the effects of SSRIs on BMD are limited, these studies showed the negative effects of these drugs on BMD $[4,5]$. In a study with bone cell culture, it was shown that the serotonergic pathway has a role in converting a mechanical stimulus into a chemical stimulus and that SSRI usage has negative effects on bone density, particularly in developing bones [6]. Richards et al. showed that SSRIs are clinically related to bone fragility, fall risk, a doubled risk of fracture, and decreasing BMD scores [7]. Functional serotonin receptors are present in osteoblasts and osteocytes. In in vitro media, these receptors stimulate the reproduction of osteoblasts in mice and facilitate differentiation in human osteoclasts. Serotonin receptors (5HT2B) aid osteogenic differentiation in cell cultures [8]. A decrease in bone mass and strength and changes in bone structure are shown in mice with serotonin transporter gene defects. Mice exposed to fluoxetine hydrochloride are shown to have impaired bone mineral content and bone formation [9]. These studies support the hypothesis that the serotonin transporters in bone cells have an important role in defining bone mass, structure, and strength.

The objectives of our study are to evaluate the effect of selective serotonin reuptake inhibitor (SSRI) therapy on bone mineral density (BMD) in postmenopausal women who are diagnosed with generalized anxiety disorder, to identify the effects on the risk factors for osteoporosis of the duration of illness and therapy, and to evaluate the effect of SSRIs on BMD.

\section{Methods}

\section{Subjects}

A total of 67 consecutive postmenopausal women between the ages of 50 and 65 years, who were admitted to the Ankara Numune Training and Research Hospital Psychiatry Department outpatient clinic, were enrolled in this study. All the patients were diagnosed with generalized anxiety disorder according to the Diagnostic and Statistical Manual of Mental Disorders (DSM)-IV-TR criteria by using Structured Clinical Interview for DSM-IV Axis I Disorders (SCID-I) and were treated with sertraline, paroxetine, or citalopram for at least 12 months. The SSRI dosage was in the therapeutic range although no dose limitation was set; the study is a naturalistic study. A score of more than seven points on the Hamilton Depression Scale; mental retardation; being diagnosed with another first-axis disorder; substance abuse including abuse of alcohol, the use of other drugs such as antipsychotics, thyroid hormone, steroids, and mood stabilizers; a disorder causing osteoporosis; a bone disease; or an endocrinological disease were the exclusion criteria for the study. A total of seven patients were excluded from the study including two patients with comorbid depression, two with hormone replacement therapy, one using steroids, one with rheumatoid arthritis, and one using antiepileptic drug.

The control group consisted of 40 healthy volunteers with no history of psychiatric disease who matched the criteria of the patients were enrolled in the study. The approval of the Ethics Committee was obtained. The patients were informed, and written informed consent forms were obtained from all of the participants.

\section{Measurements}

A sociodemographic data form was completed for all of the participants. Additionally, examination was administered to the patients, including a physical examination, height and weight measurements, and a body mass index (BMI) assessment, and a smoking history (never smokers or current/former smokers) was taken from each patient. The BMD measurements were performed in the Ankara Numune Training and Research Hospital Radiology Department. Bone mineral density assessment was performed by DXA in all of the patients at the right-hip femoral neck, trochanteric, intertrochanteric, and Ward's regions. 


\section{Structured clinical interview for DSM-IV axis I disorders}

An interview form developed by Spitzer et al. was used, Turkish reliability and validity, for the DSM-IV Axis I diagnosis that was used in the study [10].

\section{Hamilton depression scale}

A form developed by Hamilton (1960) consisting of 17 questions was used, and a score of $\geq 14$ indicates depression. The reliability and validity study of the Turkish version were conducted by Akdemir et al. [11] (It was used to exclude patients with major depressive disorder).

\section{Hamilton anxiety scale}

The form designed by Hamilton (1959) for determining the level of anxiety and distribution of symptoms in individuals was used in the study. The HAS consists of 14 questions that investigate physical and mental symptoms. The reliability and validity study of the Turkish version were conducted by Yazıc1 et al. [12].

\section{Bone mineral density}

The BMD $\left(\mathrm{g} / \mathrm{cm}^{2}\right)$ is performed by DXA in all of the patients at the right-hip femoral neck and in the trochanteric, intertrochanteric, and Ward's regions. The WHO criteria were used for osteoporosis and osteopenia. According to these criteria, a T-score $<-1$ or $>-2.5$ was defined as osteopenia, and a T-score $\leq-2.5$ was defined as osteoporosis. The T-score is the number of standard deviations (SD) from the young adult mean, and the Z-score is the number of standard deviations above or below the average bone mineral density value for women of comparable age [13].

\section{Statistical analysis}

The statistical analyses were performed using SPSS for Windows Version 11.5. The normality of the constant variables was determined by the Shapiro-Wilk test. The descriptive statistics for the constant variables were defined as the mean \pm standard deviation, the median (the width between the quarters) or the median (as the minimum and maximum), whereas the categorical variables were defined by the case number as the percentage (\%). The significance of the difference between the control and treatment groups for the mean BMI values and ages was evaluated by Student's $t$ test. The significance of the difference between the control group and the individual drug groups for the mean BMI values and ages was evaluated by a one-way ANOVA test.

The significance of the differences between the case and control T- and Z-scores and the T- and Z-scores of the smoking and non-smoking cases were determined by the MannWhitney $U$ test. The significance of the T- and Z-scores' changes in the cases and controls was determined by the Kruskal-Wallis test. If significance were detected, multiple non-parametric comparison tests were performed to identify the groups in which significance was defined. The significance of the differences in smoking and bone loss between the groups was calculated by Pearson's chi-square test. The correlation between the BMD and other variables was determined by Spearman's correlation test. Statistical significance was defined as $p<0.05$.

\section{Results}

The patients in the SSRI group (paroxetine, citalopram and sertraline) were postmenopausal and were between 50 and 65 years of age. There was no statistically significant difference between the control and the SSRI groups in terms of age and smoking history $(p>0.05)$ (Table 1$)$.

The clinical and demographic characteristics of the control and drug groups are listed in Table 2. There was no statistical significance between the control and drug groups according to the BMI and smoking history (Table 2). There was no statistically significant difference between the drug groups in terms of the duration of disease and the duration of drug use (Table 1).

The Z-scores of L2, L3, and L4 vertebrae; the total lumbar vertebral region; the intertrochanteric region; and the total femoral region and the T-scores of the femoral Ward's region were lower in the patient group than those of the identical regions in the control group. The difference was statistically significant $(p<0.05)$ (Table 2).

The median Hamilton anxiety scores of the patients were 21 (5.00) in the paroxetine group, 16.5 (9.25) in the citalopram group, and 18.5 (7.50) in the sertraline group. There was no statistically significant difference between the groups $(p>0.05)$.

The Z-scores of L2, L3, and L4 vertebrae and the total lumbar vertebral region; the T-scores of the femoral neck and the femoral trochanteric region; and the T- and Z-scores of the femoral Ward's regions in the paroxetine group were lower than those of the identical regions in the control group $(p<0.05)$ (Table 3 ).

The Z-scores of L3 and L4 vertebrae and the total lumbar vertebral regions and the T-scores of the femoral neck, trochanteric region, and femoral Ward's region were lower in the citalopram group than those of the identical regions in the control group $(p<0.05)$ (Table 3).

The Z-scores of L2, L3, and L4 vertebrae; the total lumbar vertebral region; and the femoral Ward's region and the T- and Z-scores of femoral neck, trochanteric region, intertrochanteric region, and the total femoral region were 
Table 1 Demographic characteristics of control and SSRI groups

\begin{tabular}{|c|c|c|c|c|c|}
\hline Variables & Control $(n=40)$ & Paroxetine $(n=20)$ & Citalopram $(n=20)$ & Sertraline $(n=20)$ & $p$ \\
\hline Age (year) & $56.5 \pm 4.2$ & $55.0 \pm 0.6$ & $56.9 \pm 3.2$ & $56.2 \pm 2.6$ & $0.261^{\mathrm{a}}$ \\
\hline Body Mass Index & $28.8 \pm 3.7$ & $27.2 \pm 4.6$ & $28.7 \pm 3.2$ & $26.3 \pm 3.5$ & $0.069^{\mathrm{a}}$ \\
\hline Smoking history (current/former users) & $12(30.0 \%)$ & $8(40.0 \%)$ & $7(35.0 \%)$ & $8(40.0 \%)$ & $0.830^{\mathrm{b}}$ \\
\hline Duration of disease (month) & - & $42(24-96)$ & $36(18-120)$ & $48(24-108)$ & $0.230^{\mathrm{c}}$ \\
\hline Duration of drug use (month) & - & $24(12-36)$ & $24(12-60)$ & $30(12-36)$ & $0.182^{\mathrm{c}}$ \\
\hline Mean drug dose (mg/day) & - & $30(20-40)$ & $20(10-20)$ & $62.5(50-100)$ & \\
\hline
\end{tabular}

${ }^{a}$ One-way ANOVA test

${ }^{\mathrm{b}}$ Pearson's chi-square test

${ }^{\mathrm{c}}$ Kruskal-Wallis test

lower in the sertraline group than those of the identical regions in the control group, which were all statistically significant (Table 3).

A comparison of the treatment groups and the T- and Zscores of the femoral neck, trochanteric region, total femur, and femoral Ward's region of the sertraline group were shown to be lower than those areas of the citalopram and the paroxetine groups $(p<0.05)$ (Table 3$)$.

There was a medium correlation between the BMI and the $\mathrm{Z}$-score of the L1 vertebra $(r=0.096, p<0.05)$, a low correlation between the BMI and the Z-score of the L2 vertebra ( $r=$ $0.226, p<0.05$ ), a low correlation between the BMI and the Zscore of the L4 vertebra $(r=0.210, p<0.05)$, a medium correlation between the BMI and the Z-score of the femoral neck $(r=0.347, p<0.05)$, a medium correlation between the BMI and the T- and Z-scores of the trochanteric region $(r=0.244$, $p<0.05 ; r=0,307, p<0,05)$, a medium correlation between the $\mathrm{BMI}$ and the T- and Z-scores of intertrochanteric region $(r=$ $0.334, p<0.05 ; r=0.387, p<0.05$ ), a medium correlation between the BMI and the T- and Z-scores of the total femoral region $(r=0.277, p<0.05 ; r=0.336, p<0.05)$, and a low correlation between the $\mathrm{BMI}$ and the $\mathrm{Z}$-score of the femoral Ward's region $(r=0.241, p<0.05)$. All of the correlations were statistically significant.

In the patient group, smokers had lower femoral trochanteric T-scores, femoral intertrochanteric T- and Z-scores, total femoral T- and Z-scores, and femoral Ward's region Z-scores, which were statistically significant.

Of all the patients, there was no statistically significant correlation between the duration of disease and the T- and Zscores measured at L1-L4, the total lumbar, femoral neck, femoral trochanteric, femoral intertrochanteric, total femoral, and femoral Ward's regions $(p>0.05)$.

Of all the patients, there was a medium negative correlation between the duration of treatment and the L1 vertebral T- and Z-scores $(r=-0.537, p<0.05 ; r=-0.547, p<0.05)$, a medium negative correlation with the L2 vertebral T- and Z-scores ( $r=$ $-0.508, p<0.05 ; r=-0.608, p<0.05$ ), a weak negative correlation with the L3 vertebral T- and Z-scores $(r=0.424$, $p<0.05 ; r=-0.459, p<0.05)$, a weak negative correlation with the L4 vertebral T- and Z-scores $(r=-0.396, p<0.05 ; r=$ $-0.310, p<0.05$ ), a weak negative correlation with the total lumbar vertebral T- and Z-scores $(r=-0.420, p<0.05 ; r=$ $-0.405, p<0.05$ ), a weak negative correlation between the femoral neck trochanteric region T- and Z-scores $(r=-0.406$, $p<0.05 ; r=-419, p<0,05)$, a weak negative correlation with the intertrochanteric Z-scores $(r=-0.28, p<0.05)$, a weak negative correlation with the total femoral $\mathrm{T}$ - and $\mathrm{Z}$-scores $(r=-0.328, p<0.05 ; r=-0.339, p<0.05)$, and a weak negative correlation with the femoral Ward's region T- and Z-scores ( $r=-0.401, p<0.05 ; r=-0.333, p<0.05)$.

Table 2 T- and Z-scores for the control and SSRI Groups

\begin{tabular}{lrrr}
\hline Variables & Control group & SSRI group & \multicolumn{1}{c}{$p^{\mathrm{a}}$} \\
\hline L1 T & $-0.95(1.95)$ & $-0.60(1.38)$ & 0.622 \\
L1 Z & $0.05(1.48)$ & $-0.20(1.10)$ & 0.059 \\
L2 T & $-1.40(2.33)$ & $-1.00(1.98)$ & 0.773 \\
L2 Z & $-0.15(1.63)$ & $-0.55(1.38)$ & 0.003 \\
L3 T & $-0.95(2.15)$ & $-1.10(0.80)$ & 0.303 \\
L3 Z & $0.05(1.68)$ & $-0.50(0.60)$ & $<0.001$ \\
L4 T & $-1.45(1.45)$ & $-1.20(1.10)$ & 0.927 \\
L4 Z & $-0.40(1.45)$ & $-0.80(0.80)$ & $<0.001$ \\
Total L T & $-1.40(1.70)$ & $-0.80(1.30)$ & 0.344 \\
Total L Z & $-0.20(1.30)$ & $-0.70(1.20)$ & $<0.001$ \\
Neck T & $-0.50(1.28)$ & $-0.10(1.25)$ & 0.126 \\
Neck Z & $0.45(1.38)$ & $0.35(1.68)$ & 0.057 \\
Troch T & $-0.30(1.65)$ & $0.00(1.28)$ & 0.359 \\
Troch Z & $0.15(1.48)$ & $0.05(1.30)$ & 0.118 \\
Inter T & $0.00(1.30)$ & $-0.20(1.10)$ & 0.053 \\
Inter Z & $0.30(1.13)$ & $-0.10(1.10)$ & $<0.001$ \\
Total F T & $-0.30(1.45)$ & $-0.40(0.98)$ & 0.772 \\
Total F Z & $0.20(1.20)$ & $-0.10(1.20)$ & 0.002 \\
Ward's F T & $-0.75(1.68)$ & $-0.40(1.58)$ & 0.009 \\
Ward's F Z & $0.75(1.23)$ & $0.65(1.68)$ & 0.677 \\
\hline
\end{tabular}

${ }^{\text {a } M a n n-W h i t n e y ~} U$ test 
Table 3 T- and Z-scores for the control and drug groups

\begin{tabular}{lllllr}
\hline Variables & Control & Paroxetine & Citalopram & Sertraline & $p^{\mathrm{a}}$ \\
\hline L1 T & $-0.95(1.95)$ & $-0.60(0.80)$ & $-0.65(2.28)$ & $-0.75(2.03)$ & 0.326 \\
L1 Z & $0.05(1.48)$ & $-0.40(0.60)$ & $-0.10(1.10)$ & $-0.40(2.10)$ & 0.075 \\
L2 T & $-1.40(2.33)$ & $-0.50(1.90)$ & $-1.50(2.98)$ & $-1.00(1.28)$ & 0.992 \\
L2 Z & $-0.15(1.63)^{\mathrm{b}, \mathrm{c}}$ & $-0.40(1.40)^{\mathrm{b}}$ & $-0.30(1.80)$ & $-0.95(0.88)^{\mathrm{c}}$ & 0.021 \\
L3 T & $-0.95(2.15)$ & $-1.00(0.80)$ & $-1.00(1.40)$ & $-1.20(0.75)$ & 0.622 \\
L3 Z & $0.05(1.68)^{\mathrm{b}, \mathrm{c}, \mathrm{d}}$ & $-0.50(0.60)^{\mathrm{b}}$ & $-0.50(1.50)^{\mathrm{d}}$ & $-0.60(0.90)^{\mathrm{c}}$ & 0.002 \\
L4 T & $-1.45(1.45)$ & $-1.20(0.60)$ & $-1.20(1.05)$ & $-1.20(1.35)$ & 0.847 \\
L4 Z & $-0.40(1.45)^{\mathrm{b}, \mathrm{c}, \mathrm{d}}$ & $-0.80(0.50)^{\mathrm{b}}$ & $-0.80(0.65)^{\mathrm{d}}$ & $-0.85(1.48)^{\mathrm{c}}$ & 0.004 \\
Total L T & $-1.40(1.70)$ & $-0.80(1.20)$ & $-0.80(1.28)$ & $-1.30(1.15)$ & 0.756 \\
Total L Z & $-0.20(1.30)^{\mathrm{b}, \mathrm{c}, \mathrm{d}}$ & $-0.70(0.68)^{\mathrm{b}}$ & $-0.70(1.18)^{\mathrm{d}}$ & $-0.70(1.48)^{\mathrm{c}}$ & 0.004 \\
Neck T & $-0.50(1.28)^{\mathrm{b}, \mathrm{c}, \mathrm{d}}$ & $0.30(0.50)^{\mathrm{b}, \mathrm{e}}$ & $0.30(0.80)^{\mathrm{d}, \mathrm{f}}$ & $-0.95(0.38)^{\mathrm{c}, \mathrm{e}, \mathrm{f}}$ & $<0.001$ \\
Neck Z & $0.45(1.38)^{\mathrm{c}}$ & $0.40(0.50)^{\mathrm{e}}$ & $0.40(0.90)^{\mathrm{f}}$ & $-0.80(0.55)^{\mathrm{c}, \mathrm{e}, \mathrm{f}}$ & $<0.001$ \\
Troch T & $-0.30(1.65)^{\mathrm{b}, \mathrm{c}, \mathrm{d}}$ & $0.10(0.50)^{\mathrm{b}, \mathrm{e}}$ & $0.05(0.90)^{\mathrm{d}, \mathrm{f}}$ & $-0.95(1.40)^{\mathrm{c}, \mathrm{e}, \mathrm{f}}$ & $<0.001$ \\
Troch Z & $0.15(1.48)^{\mathrm{c}}$ & $0.50(0.30)^{\mathrm{e}}$ & $0.50(1.18)^{\mathrm{f}}$ & $-0.70(0.93)^{\mathrm{c}, \mathrm{e}, \mathrm{f}}$ & $<0.001$ \\
Inter T & $0.00(1.30)^{\mathrm{c}}$ & $-0.20(0.40)^{\mathrm{e}}$ & $-0.20(1.48)^{\mathrm{f}}$ & $-0.95(0.55)^{\mathrm{c}, \mathrm{e}, \mathrm{f}}$ & $<0.001$ \\
Inter Z & $0.30(1.13)^{\mathrm{c}}$ & $0.30(0.40)^{\mathrm{e}}$ & $0.30(1.10)^{\mathrm{f}}$ & $-0.90(0.55)^{\mathrm{c}, \mathrm{e}, \mathrm{f}}$ & $<0.001$ \\
Total F T & $-0.30(1.45)^{\mathrm{c}}$ & $-0.30(0.60)^{\mathrm{e}}$ & $-0.30(1.33)^{\mathrm{f}}$ & $-0.90(0.50)^{\mathrm{c}, \mathrm{e}, \mathrm{f}}$ & $<0.001$ \\
Total F Z & $0.20(1.20)^{\mathrm{c}}$ & $0.20(0.20)^{\mathrm{e}}$ & $0.20(1.53)^{\mathrm{f}}$ & $-1.00(0.20)^{\mathrm{c}, \mathrm{e}, \mathrm{f}}$ & $<0.001$ \\
Ward's F T & $-0.75(1.68)^{\mathrm{b}, \mathrm{d}}$ & $0.50(1.00)^{\mathrm{b}, \mathrm{e}}$ & $0.50(1.30)^{\mathrm{d}, \mathrm{f}}$ & $-1.10(0.88)^{\mathrm{e}, \mathrm{f}}$ & $<0.001$ \\
Ward's F Z & $0.75(1.23)^{\mathrm{b}, \mathrm{c}}$ & $1.30(0.60)^{\mathrm{b}, \mathrm{e}}$ & $1.10(0.90)^{\mathrm{f}}$ & $-0.50(0.30)^{\mathrm{c}, \mathrm{e}, \mathrm{f}}$ & $<0.001$ \\
\hline & & & &
\end{tabular}

There was no statistically significant correlation between the Hamilton anxiety scores and the T- and Z-scores of L1-L4, the total lumbar, the femoral neck, the femoral trochanteric, femoral intertrochanteric, total femoral, and femoral Ward's regions of the patients $(p>0.05)$.

\section{Discussion}

The most frequent psychiatric comorbidities observed in patients with generalized anxiety disorder are major depression and dysthymia. The comorbidity is $62.4 \%$ with depression and $40 \%$ with dysthymia [14].

Whereas some studies that investigated the relationship between depression and osteoporosis reported a decrease in BMD, others reported that there was no significant difference in BMD between the patient and control groups [15-21]. Depression has effects on bone density by changing the hypothalamic-pituitaryadrenal axis and increasing proinflammatory cytokines such as interleukin-6 and TNF- $\alpha$ [22]. The non-inclusion of patients with a score lower than seven on the HDS is important to exclude the confounding effects of depression on BMD.

The median Hamilton anxiety scores were 21.0 in the paroxetine group, 16.5 in the citalopram group, and 18.5 in the sertraline group, which were not significantly correlated with the BMD scores. No study was found in the literature regarding this topic in older patients. Dorn et al. investigated the BMD scores in adolescent girls with anxiety and depressive symptoms and found that lower BMD scores were associated with higher anxiety levels [3]. This result might be a consequence of not excluding depression in this study.

Nicotine addiction is found in $25.8 \%$ of the occurrence of anxiety disorders in the literature. It has been reported that nicotine helps in coping with stress by increasing the ACTH and cortisol levels and that tobacco consumption increases the risk of osteoporosis, hip fracture, and early menopause [23, 24]. In our study, the T-scores of the femoral trochanteric region, the $\mathrm{T}$ - and Z-scores of the intertrochanteric region, the total femoral T- and Z-scores, and the femoral Ward's Z-scores were lower in smoking individuals than in non-smoking individuals.

Osteoporosis is more prevalent in obese individuals [25]. In our study, the medium BMI scores were over $25 \mathrm{~kg} / \mathrm{m}^{2}$ in the SSRI and control groups. Because there was no significant statistical difference in the BMI between the groups, it is important to equalize the effects of the BMI on BMD. Studies have shown a positive correlation between BMD scores and the BMI [26]. Our study is consistent with previous studies showing a positive correlation between the BMI and BMD scores. The results support the hypothesis that a higher BMI is a protective factor for osteoporosis.

The results of studies investigating the effects of SSRI use on BMD vary. Richards et al. evaluated the association between SSRI use and BMD and fractures; they reported that SSRI use was associated with decreased BMD, an increased risk of falling, and a 2-fold increased risk of a clinical fragility fracture [7]. In a prospective cohort study by Diem et al. of 
2,722 elderly women, including SSRI users, TCA users, and non-user healthy controls, the hip BMD was measured at the beginning of treatment and at the end of 4 years, and an increased rate of bone loss at the hip was shown in the SSRI users compared to the TCA users and the non-user control group [5]. The finding in our study that the BMD scores of L2, L3, and L4 vertebrae, the total lumbar vertebra, the total femoral neck, femoral trochanteric, and femoral Ward's regions in patients using SSRIs were significantly lower than those of the identical regions in the control group was consistent with results in the studies mentioned [4, 5, 7, 27, 28].

Additionally, studies have shown no significant difference in the BMD scores during SSRI treatment. In these studies, the effects of SSRIs and TCAs on BMD were usually assessed together [29]. In a study by Spangler et al., involving 50-79year-old postmenopausal women, the bone mineral density of the hip, spine, and whole body was measured at baseline and three years, and no statistically significant associations were observed between depressive symptoms or antidepressant (SSRI or TCA) therapy and 3-year changes in BMD or fracture risk [30]. In another study by Cummings et al., the effects of antidepressant use on BMD were evaluated in women over 65 years of age. The BMD values of antidepressant users were reported to be similar to those of non-antidepressant users [31]. The results obtained in these studies and the result of our study might differ because the effects of SSRIs and TCAs on the BMD have not been evaluated separately. In a study by Halbreich et al., involving patients on psychotropic therapy (antidepressants or antipsychotics) for schizophrenia and affective disorders, the lumbar vertebral (L2-L4) BMD values of the patients were compared with the age- and genderexpected values, and their BMD values were found to be lower than the expected values, a finding that was particularly more pronounced in males [32]. Because untreated patients were not included in this study, it is not clear whether the results are diagnosis related, and/or treatment related [33].

The different results obtained from the studies examining the effects of antidepressant use on BMD might have many causes. The first of these reasons might be the different methods used in the studies. In some studies, the BMD scores were compared with those of healthy subjects, whereas in other studies, the BMD results were evaluated at the beginning of the study and then during the study. Another factor could be the different number of subjects enrolled in the studies. The other element that is difficult to control might be that the BMD could be affected by hormone levels, nutrition, physical activity, smoking, and alcohol. The most important fact might be that the medication used by the subjects for other medical reasons should be detected for the BMD scores which is a long process [34-36].

In our study, the T- and Z-scores of the sertraline group at the femoral neck region, the femoral trochanteric region and the intertrochanteric region, the total femoral scores, and the scores in the femoral Ward's region were lower than those of the citalopram and paroxetine groups. This difference could be explained by the longer duration of disease and the longer treatment period in the sertraline group. No studies have performed subgroup analyses of the drugs used in the treatment.

We did not find a statistically significant correlation between the duration of disease and the $\mathrm{T}$ - and $\mathrm{Z}$-scores of $\mathrm{L} 1-$ L4, femoral neck, intertrochanteric region, trochanteric region, total femur, and femoral Ward's region. We did not find any study in the literature that investigated the effects of the duration of disease and the duration of treatment on the BMD scores. Not finding a correlation between the duration of disease, disease severity and BMD scores and discovering a negative correlation between the duration of treatment and BMD scores are hypothesized to be related to low BMD scores resulting from SSRI treatment.

Our study is the first study to perform a subgroup analysis of SSRI effects on BMD scores. The strengths of our study are as follows: there are no statistically significant differences between the groups in terms of factors that might affect BMD scores such as the BMI and smoking. To equalize the effects on the BMD scores, the hormone levels were not detected because all of the subjects in the study were postmenopausal women.

The limitations of our study are as follows: being unable to document the BMD changes related to postmenopausal osteoporosis because sufficient data regarding the menopause duration of the women were not obtained, not enlisting the antidepressant treatment, and not knowing the BMD scores before the study. BMD might be decreased with various lifestyle variables. Our study design did not include nutrition factors, physical activity, family history of bone loss, calcium and vitamin D deficiency, and hormonal parameters. Therefore, it is difficult to test SSRI treatment as a single variable. Additional prospective and randomized, placebo controlled studies that include these factors should be performed. This study contained a small number of subjects, and a particular group of subjects were enrolled in the study; therefore, these results could not be generalized to the general population, which is another reason for more comprehensive studies to be performed.

\section{Conflicts of interest None.}

Open Access This article is distributed under the terms of the Creative Commons Attribution Noncommercial License which permits any noncommercial use, distribution, and reproduction in any medium, provided the original author(s) and the source are credited.

\section{References}

1. World Health Organization (1994) Assessment of fracture risk and its application to screening for postmenopausal osteoporosis: report of a WHO study group (meeting held in Rome from 22 to 25 June 1992) 
2. Patterson-Buckendahl P, Rusnak M, Fukuhara K, Kvetnansky R (2001) Repeated immobilization stress reduces rat vertebral bone growth and osteocalcin. Am J Physiol Regul Integr Comp Physiol 280(1):79-86

3. Dorn LD, Susman EJ, Pabst S, Huang B, Kalkwarf H, Grimes S (2008) Association of depressive symptoms and anxiety with bone mass and density in ever-smoking and never-smoking adolescent girls. Arch Pediatr Adolesc Med 162(12):1181-1188

4. Haney EM, Chan BK, Diem SJ, Ensrud KE, Cauley JA, BarrettConnor E, Orwoll E, Bliziotes MM (2007) Association of low bone mineral density with selective serotonin reuptake inhibitor use by older men. Arch Intern Med 167(12):1246-1251

5. Diem SJ, Blackwell TL, Stone KL, Yaffe K, Haney EM, Bliziotes MM, Ensrud KE (2007) Use of antidepressants and rates of hip bone loss in older women: the study of osteoporotic fractures. Arch Intern Med 167(12):1240-1245

6. Westbroek I, Van der Plas A, De Rooij KE, Klein-Nulend J, Nijweide PJ (2001) Expression of serotonin receptors in bone. J Biol Chem 276(31):2891-2898

7. Richards JB, Papaioannou A, Adachi JD, Joseph L, Whitson HE, Prior JC, Goltzman D (2007) Effect of selective serotonin reuptake inhibitors on the risk of fracture. Arch Intern Med 167(2):188-194

8. Locker M, Bitard J, Collet C, Poliard A, Mutel V, Launay JM, Kellerman O (2006) Stepwise control of osteogenic differentiation by 5 -HT (2B) receptor signaling: nitric oxide production and phospholipase A2 activation. Cell Signal 18(5):628-639

9. Warden SJ, Robling AG, Sanders MS, Bliziotes MM, Turner CH (2005) Inhibition of the serotonin (5-hydroxytryptamine) transporter reduces bone accrual during growth. Endocrinology 146(2):685-693

10. Öztürkçigil A, Aydemir Ö, Yıldız M, Danaca AE, Köroğlu E (1999) DSM-IV Eksen Bozuklukları için Yapılandırılmış Klinik Görüşmenin Türkçeye Uyarlanması ve Güvenirlik Çalışması. İlaç Tedavisi Dergisi 12:233-266

11. Akdemir A, Örsel S, Dağ İ, Türkçapar H, İșcan N, Özbay H (1996) Hamilton depresyon derecelendirme ölçeği (HDDÖ)'nin geçerliği, güvenirliği ve klinikte kullanımı. Psikiyatri Psikoloji Psikofarmakoloji Dergisi 4(4):251-259

12. Yazıcı MK, Demir B, Tanrıverdi N (1998) Hamilton Anksiyete Degerlendirme Ölceği; Degerlendiriciler Arası Güvenirlik ve Geçerlik Çalısması. Turk Psikiyatri Derg 9:114-117

13. Kutsal Gökçe Y (1998) Osteoporozda Görüntüleme Yöntemleri ve Histomorfometre. İstanbul, pp 81-103

14. Witchen HU, Zhao S, Kessler RC, Eaton WW (1994) DSM-III-R generalized anxiety disorder in the National Comorbidity Survey. Arch Gen Psychiatry 51(5):355-364

15. Özsoy S, Eșel E, Turan T, Kula M, Demir H, Kartalcı Ș, Kökbudak Z (2005) Depresyonlu hastalarda kemik mineral yoğunluğunda değișiklik var mı? Turk Psikiyatri Derg 16(2):77-82

16. Michelson D, Stratakis C, Hill L, Reynolods J, Galliven E, Chrousos G, Gold P (1996) Bone mineral density in women with depression. N Engl J Med 335(16):1176-1181

17. Yazııı KM, Akıncı A, Sütçü A, Özçakar L (2003) Bone mineral density in premenopausal women with major depressive disorder. Psychiatry Res 117(3):271-275

18. Williams LJ, Henry MJ, Berk M, Dodd S, Jacka FN, Kotowicz MA, Nicholson GC, Pasco JA (2008) Selective serotonin reuptake inhibitor use and bone mineral density in women with a history of depression. Int Clin Psychopharmacol 23(2):84-87
19. Wu Q, Magnus JH, Liu J, Bencaz AF, Hentz JG (2009) Depression and low bone mineral density: a meta-analysis of epidemiologic studies. Osteoporos Int 20(8):1309-1320

20. Moura C, Bernatsky S, Abrahamowicz M, Papaioannou A, Bessette L, Adachi J, Goltzman D, Prior J, Kreiger N, Towheed T, Leslie WD, Keiser S, Ioannidis G, Pickard L, Fraser LA, Rahme E (2014) Antidepressant use and 10-year incident fracture risk: the population-based Canadian Multicentre Osteoporosis Study (CaMoS). Osteoporos Int 25(5):1473-1481

21. Erez HB, Weller A, Vaisman N, Kreitler S (2012) The relationship of depression, anxiety and stress with low bone mineral density in postmenopausal women. Arch Osteoporos 7(1-2):247-255

22. Dowlati Y, Herrmann N, Swardfager W, Liu H, Sham L, Reim EK, Lanctôt KL (2010) A meta-analysis of cytokines in major depression. Biol Psychiatry 67(5):446-457

23. Pomerleau OF, Pomerleau CS (1991) Research on stress and smoking: progress and problems. Br J Addict 86(5):599-603

24. Ortego-Centeno N, Munoz-Torres M, Jodar E, Hernandez-Quero J, Jurado-Duce A, de la Higuera T-PJ (1997) Effect of tobacco consumption on bone mineral density in healthy young males. Calcif Tissue Int 60(6):496-500

25. Lindsay R, Cosman F (2001) Osteoporozis. In: Braundwald E, Fauci AS, Isselbacher KJ (eds) Harrison's principles of internal medicine. McGraw- Hill, New York, p 342

26. Meaney AM, Smith S, Howes OD, O'Brien M, Murray RM, O'Keane V (2004) Effects of long-term prolactin-raising antipsychotic medication on bone mineral density in patients with schizophrenia. Br J Psychiatry 184:503-508

27. Chen F, Hahn TJ, Weintraub NT (2012) Do SSRIs play a role in decreasing bone mineral density? JAMDA 13(5):413-417

28. Rabenda $V$, Nicolet $D$, Beaudart $C$, Bruyère $O$, Reginster JY (2013) Relationship between use of antidepressants and risk of fractures: a meta-analysis. Osteoporos Int 24(1):121-137

29. Ginzburg R, Rosero E (2009) Risk of fractures with selective serotonin-reuptake inhibitors or tricyclic antidepressants. Ann Pharmacother 43(1):98-103

30. Spangler L, Scholes D, Brunner RL, Robbins J, Reed SD, Newton KM, Melville JL, Lacroix AZ (2008) Depressive symptoms, bone loss, and fractures in postmenopausal women. J Gen Intern Med 23(5):567-574

31. Cummings SR, Cawthon PM, Ensrud KE, Cauley JA, Fink HA, Orwoll ES (2006) BMD and risk of hip and nonvertebral fractures in older men: a prospective study and comparison with older women. J Bone Miner Res 21(10):1550-1556

32. Halbreich U, Palter S (1996) Accelerated osteoporosis in psychiatric patients: possible pathophysiological processes. Schizophr Bull 22(3):447-454

33. Halbreich U, Rojansky N, Palter S, Hreshchyshyn M, Kreeger J, Bakhai Y, Rosan R et al (1995) Decreased bone mineral density in medicated psychiatric patients. Psychosom Med 57(5):485-491

34. Abraham G, Paing WW, Kaminski J, Joseph A, Kohegyi E, Josiassen RC (2003) Effects of elevated serum prolactin on bone mineral density and bone metabolism in female patients with schizophrenia: a prospective study. Am J Psychiatry 160(9):1618-1620

35. Keely EJ, Reiss JP, Drinkwater DT, Faiman C (1997) Bone mineral density, sex hormones, and long-term use of neuroleptic agents in men. Endocr Pract 3(4):209-213

36. Chau K, Atkinson SA, Taylor VH (2012) Are selective serotonin reuptake inhibitors a secondary cause of low bone density? J Osteoporos 2012 